\title{
Linear Programming as a tool to fulfill nutritional requirements using the Honduran Basic Food Basket
}

\author{
Daniel Montenegro, M. Sc ${ }^{1}$ \\ ${ }^{1}$ Universidad Tecnológica Centroamericana (UNITEC), Facultad de Ingeniería, Departamento de Ingeniería Industrial y de \\ Sistemas, Tegucigalpa, Honduras, 11101, daniel.guerrero@unitec.edu.hn
}

\begin{abstract}
Honduras is a country with a high poverty rate which, amongst other factors, is a key contributor to problems of malnutrition in the population. Linear programming was utilized as a tool to determine the best combination of items of the essential Basic Food Basket (BFB) established by the government in order to fulfill the nutritional requirements of a family unit. In addition to information about the essential BFB, food composition tables and dietary reference intakes as well as upper intake levels were researched in order to formulate the mathematical model. Minimum wage information was also collected as well as food based dietary guidelines for Honduras. Three models were created with varying degrees of constraints and solved utilizing the Solver add in of Microsoft Excel. Optimum solution across all models only chose 33\% or less of the food items in the essential BFB; the third model showed that for an average family of 4 the minimum wage is used up almost in its entirety which indicates that the BFB is not affordable for the majority of the population.
\end{abstract}

Keywords-Linear Programming, Basic Food Basket, Minimum Wage, Poverty, Nutrition

\section{INTRODUCTION}

Honduras is a developing country located in Central America which has a population of 9.012 million people [1]. Honduras also has one of the highest poverty rates in the world with an estimated $60.9 \%$ of the population living in poverty by 2016 [2], this fact has been identified by the World Food Programme as the root of chronic food insecurity in the country [1].

The minimum wage in Honduras varies according to two major factors which are: economic sector of the company (agriculture, mining, manufacturing, energy production, construction, commerce, transport, finance, service industry and health) and the number of total employees each company has, segmenting each one in 4 ranges (1-10 employees, $11-50$, $51-150$ and 151 upwards); the minimum wage is also presented in 3 ways which are: monthly minimum wage, standard 8 hours daily shift and hourly wage [3]. The finance sector has the highest minimum wage compared to every other sector and the agriculture sector has the lowest minimum wage with a difference of L. 3,875.28 under the monthly wage for companies with more than 151 employees. The labor force by occupation estimated in 2015 was: agriculture representing $39.2 \%$, industry (which includes mining, manufacturing, energy production and construction) $20.9 \%$ and services (which includes finance, transportation and all other economic activities that do not produce material goods) $39.8 \%$ [4]. Agriculture alone has the highest labor force in the country, yet it is the economic sector with the lowest minimum wage across every range.

The average household size in Honduras consists of 3.9 members; a key part of the household definition is that it's a group of persons that make common provisions of food, shelter and other essentials for living [5]. The basic food basket (BFB) of a country includes the necessary goods to meet the nutritional needs of the population and has been used to determine the extreme poverty line in conjunction with minimum wage information [6]. The essential BFB in Honduras, which includes 30 items stands at an average of L. 5,740.89 per month for the first week of February 2019 [7]. It's worth noting that the BFB is also expressed in lempiras (L.) per person [8] and that the average income per capita, per household is L. 3,365 [9].

FAO, IFAD, UNICEF, EFP and WHO [10] state that food insecurity "contributes to both overweight and obesity, as well as undernutrition". Their work also mentions the existence a relationship between food insecurity and malnutrition indicators due to factors such as not having access to the necessary food because of lack of money and other resources. Taking this into account and the current state of poverty in Honduras the World Food Programme has found that there exists chronic malnutrition of $23 \%$ of children aged 6-59 months [1]. Uncertain access to food at a household means inadequate infant and child feeding which in turn means insufficient intake of calories, nutrients, vitamins and minerals resulting in child stunting and wasting [10]. Stunting can be defined as impaired growth and development that children experience from poor nutrition and can have consequences such as poor educational performance, low adult wages and increased risk of nutrition related chronic diseases in adult life [11].

Nutritional education and knowledge are not widespread amongst the population, especially the ones that live in poverty and extreme poverty; with the economic constraints presented to them an "eat to survive" mentality can develop, and this can hinder proper nutrient distribution. The main goal of this study is to determine if there exist a combination of food items from the essential BFB that can provide sufficient nutrients to try and reduce stunting as much as possible in children up to 3 years taking into account the various restraints that the majority of the population has. It also aims to determine how an average household and family unit needs to use its resources to achieve adequate nutrient distribution.

Digital Object Identifier (DOI):

http://dx.doi.org/10.18687/LACCEI2019.1.1.342

ISBN: 978-0-9993443-6-1 ISSN: 2414-6390

$17^{\text {th }}$ LACCEI International Multi-Conference for Engineering, Education, and Technology: "Industry, Innovation, And Infrastructure for Sustainable Cities and Communities", 24-26 July 2019, Jamaica. 


\section{METHODOLOGY}

\section{A. Linear Programming}

Linear programming (LP) consists of an algorithm that translates a real-life problem into a mathematical model. This model is made up by decision variables which are the unknowns of the problem; an objective function which can have the goal to maximize or minimize a value; and constraints that are given by the limited resources available or requirements that have to be met in order to solve the problem [12].

Linear programming has been used by various authors in works regarding BFB composition. Arnaut-Berilo, Delalic and Huseinbasic [13] developed a nutritional analysis for the BFB in Bosnia and Herzegovina; Nykänen, et al. [14] made a similar model for cost minimized diets for low income Ghanaian families which besides optimizing looked for a solution that was culturally acceptable and included "wild" food items that were available to certain communities that lived in a rural setting; Parlesak, et al. [15] used linear programming to develop a cost minimized nutritionally adequate health promoting food baskets within the greater Copenhagen area for a family of four also taking into account cultural acceptability; Santos et. Al [16] implemented similar methodology to determine food choices to meet nutrient recommendations for adult Brazilian population. As can be seen the linear programming approach has been used in countries that are vastly different both geographically and culturally around the world. It is worth noting that not every one of these studies have considered a cost minimized diet and that some works like the one presented by Donati et al. [17] also add environmental objectives which the current work does not.

In addition to some of the methodology used in the studies mentioned above, for the present study three different mathematical models were made with the goal of minimizing the total weight of food consumed in one day while fulfilling nutritional requirements with the following differences:

1. The first model does not consider a cost restraint and just aims to reach the Dietary Reference Intakes (DRI) and to not breach the Upper Intake Levels (UL) of various nutrients, vitamins and elements. This model is based on the nutritional requirements of a young child aged 1-3 years old.

2. The second model considers the cost constraint for each of the food items presented as well as recommended guidelines for food consumption in Honduras [18] for a young child aged 1-3 years old.

3. The final model changes the focus to present a more accurate approach of a standard Honduran family which consist of 4 people. Household composition data [9] shows that $62 \%$ of homes with children under 15 have both parents, therefore a family unit of both parents (male and female) and two children under 15 (male and female) was used. Average age of men and woman was used to determine DRI and UL of the parents.

\section{B. Essential BFB}

The essential BFB items and the price associated with each one was obtained from Secretaría de Desarrollo Económico and can be observed in table 1. It's worth noting that the prices of each item are the average of 6 different selling points as presented in the document and were modified, so all were represented in the same unit which is lempiras per gram.

Table 1

Essential BFB Items

\begin{tabular}{|c|l|c|}
\hline \multicolumn{2}{|c|}{ Item } & $\begin{array}{c}\text { Price } \\
\text { (L./g) }\end{array}$ \\
\hline 1 & Beef Chop & 0.14991 \\
\hline 2 & Beef Rib & 0.11317 \\
\hline 3 & Pork Rib & 0.11611 \\
\hline 4 & Chicken without giblets & 0.05232 \\
\hline 5 & White fish & 0.06063 \\
\hline 6 & Milk & 0.02055 \\
\hline 7 & Milk powder & 0.20931 \\
\hline 8 & Pasta & 0.03275 \\
\hline 9 & Sour Cream & 0.06750 \\
\hline 10 & Fresh Cheese & 0.09421 \\
\hline 11 & Yellow Onion & 0.03007 \\
\hline 12 & Tomato & 0.02607 \\
\hline 13 & Potato & 0.01984 \\
\hline 14 & Cassava & 0.01503 \\
\hline 15 & Cabbage & 0.00956 \\
\hline 16 & Ripe Plantain & 0.04211 \\
\hline 17 & Orange & 0.02042 \\
\hline 18 & Banana & 0.01486 \\
\hline 19 & Red beans & 0.02603 \\
\hline 20 & White rice & 0.02186 \\
\hline 21 & White sugar & 0.02144 \\
\hline 22 & Ground coffee & 0.09581 \\
\hline 23 & Medium sized egg & 0.04733 \\
\hline 24 & Tomato sauce & 0.05975 \\
\hline 25 & Oil & 0.06239 \\
\hline 26 & Lard & 0.03583 \\
\hline 27 & Salt & 0.01689 \\
\hline 28 & Corn Tortilla & 0.03333 \\
\hline 29 & Loaf of bread & 0.06741 \\
\hline 30 & Juice & 0.03086 \\
\hline
\end{tabular}

The items presented above were utilized as the decision variables in all three mathematical models since the main goal was to choose the best combination of essential BFB items.

\section{Food Composition data}

Food composition data was obtained from the Instituto de Nutrición de Centro America y Panama [19] for each one of the essential BFB mentioned in table 1. This data was used to formulate the models constraints, each constraint contained only the variables that would actively contribute to the overall intake of each nutrient and macronutrient. Variables could be present in different constraints depending on their composition.

$17^{\text {th }}$ LACCEI International Multi-Conference for Engineering, Education, and Technology: "Industry, Innovation, And Infrastructure for Sustainable Cities and Communities", 24-26 July 2019, Jamaica. 


\section{Dietary Reference Intakes}

Dietary Reference Intakes (DRI) as stated by U.S department of Health and Human Services "is the general term for a set of reference values used to plan and assess nutrient intakes of healthy people". DRI vary by gender and age groups and include Recommended Dietary Allowance (RDA) which is the average daily intake to meet nutrient requirements; Adequate intakes (AI) which are levels established when there is not enough evidence to generate a RDA; and Tolerable Upper Intake Level (UL) which is the maximum daily intake unlikely to cause adverse health effects [20].

The DRI tables used as part of this study were: Recommended Dietary Allowances and Adequate Intakes, Elements; Recommended Dietary Allowances and Adequate Intakes, Vitamins; Recommended Dietary Allowances and Adequate Intakes, Total Water and Macronutrients; Tolerable Upper Intake Levels Vitamins; and Tolerable| Upper Intake Levels, Elements. The nutritional components selected from these tables were only the ones that were also present in the food composition database and they were used in order to formulate some of the constraints of the mathematical models.

The dietary reference intakes used in this study can be seen in table 2 and upper intake levels in table 3.

Table 2

\begin{tabular}{|c|c|c|c|c|c|c|}
\hline & \multicolumn{6}{|c|}{ Dietary reference intakes } \\
\hline & g/day & $\begin{array}{l}\text { Child } \\
1-3 \mathrm{y}\end{array}$ & $\begin{array}{c}\text { Male } \\
31-50 \mathrm{y}\end{array}$ & $\begin{array}{c}\text { Female } \\
31-50 \text { y }\end{array}$ & $\begin{array}{l}\text { Male } \\
9-13 \text { y }\end{array}$ & $\begin{array}{l}\text { Female } \\
9-13 \text { y }\end{array}$ \\
\hline \multirow{4}{*}{ 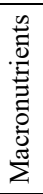 } & Water & 1300 & 3700 & 2700 & 2400 & 2100 \\
\hline & Carbohydrates & 130 & 130 & 130 & 130 & 130 \\
\hline & Fiber & 19 & 38 & 25 & 31 & 26 \\
\hline & Protein & 13 & 56 & 46 & 34 & 34 \\
\hline \multirow{8}{*}{ 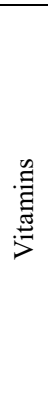 } & Vitamin A & 0.0003 & 0.0009 & 0.0007 & 0.0006 & 0.0006 \\
\hline & Vitamin C & 0.015 & 0.09 & 0.075 & 0.045 & 0.045 \\
\hline & Thiamin & 0.0005 & 0.0012 & 0.0011 & 0.0009 & 0.0009 \\
\hline & Riboflavin & 0.0005 & 0.0013 & 0.0011 & 0.0009 & 0.0009 \\
\hline & Niacin & 0.006 & 0.016 & 0.014 & 0.012 & 0.012 \\
\hline & Vitamin B6 & 0.0005 & 0.0013 & 0.0013 & 0.001 & 0.001 \\
\hline & Folate & 0.00015 & 0.0004 & 0.0004 & 0.0003 & 0.0003 \\
\hline & Vitamin B12 & 0.000000 & 0.0000024 & 0.0000024 & 0.0000018 & 0.0000018 \\
\hline \multirow{7}{*}{ 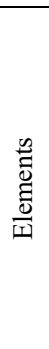 } & Calcium & 0.70 & 1.00 & 1.00 & 1.30 & 1.30 \\
\hline & Iron & 0.0070 & 0.0080 & 0.0180 & 0.0080 & 0.0080 \\
\hline & Magnesium & 0.0800 & 0.4200 & 0.3200 & 0.2400 & 0.2400 \\
\hline & Phosphorus & 0.4600 & 0.7000 & 0.7000 & 1.2500 & 1.2500 \\
\hline & Zinc & 0.0030 & 0.0110 & 0.0080 & 0.0080 & 0.0080 \\
\hline & Potassium & 3 & 4.7 & 4.7 & 4.5 & 4.5 \\
\hline & Sodium & 1 & 1.5 & 1.5 & 1.5 & 1.5 \\
\hline
\end{tabular}

Table 3

Upper intake levels

\begin{tabular}{|c|c|c|c|c|c|c|}
\hline & g/day & $\begin{array}{l}\text { Child } \\
1-3 y\end{array}$ & $\begin{array}{c}\text { Male } \\
31-50 y\end{array}$ & $\begin{array}{l}\text { Female } \\
31-50 \text { y }\end{array}$ & $\begin{array}{l}\text { Male } \\
9-13 \text { y }\end{array}$ & $\begin{array}{l}\text { Female } \\
9-13 \text { y }\end{array}$ \\
\hline \multirow{8}{*}{ 胥 } & Vitamin A & 0.0006 & 0.003 & 0.003 & 0.0017 & 0.0017 \\
\hline & Vitamin C & 0.4 & 2 & 2 & 1.2 & 1.2 \\
\hline & Thiamin & ND & ND & ND & ND & ND \\
\hline & Riboflavin & ND & ND & ND & ND & ND \\
\hline & Niacin & 0.01 & 0.035 & 0.035 & 0.02 & 0.02 \\
\hline & Vitamin B6 & 0.03 & 0.1 & 0.1 & 0.06 & 0.06 \\
\hline & Folate & 0.0003 & 0.001 & 0.001 & 0.0006 & 0.0006 \\
\hline & Vitamin B12 & ND & ND & ND & ND & ND \\
\hline \multirow{7}{*}{ 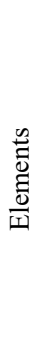 } & Calcium & 3 & 3 & 3 & 3 & 3 \\
\hline & Iron & 0.040 & 0.045 & 0.045 & 0.040 & 0.040 \\
\hline & Magnesium & 0.065 & 0.350 & 0.350 & 0.350 & 0.350 \\
\hline & Phosphorus & 3.0 & 4.0 & 4.0 & 4.0 & 4.0 \\
\hline & Zinc & 0.007 & 0.040 & 0.040 & 0.023 & 0.023 \\
\hline & Potassium & ND & ND & ND & ND & ND \\
\hline & Sodium & 1.5 & 2.3 & 2.3 & 2.2 & 2.2 \\
\hline
\end{tabular}

\section{E. Minimum wage data}

Minimum wage data was obtained from La Gaceta which the official newspaper of the Honduras government and can be seen in table 2 [3]. Minimum wage data was only used for models 2 and 3 , the wage information used was the one corresponding to the agriculture economic sector for businesses with more than 151 employees since a big part of the population works here.

\section{F. Solver}

Microsoft Excel was used in order to solve all three mathematical models by using its Solver add-in which allows to input linear programming data and obtain an optimum solution.

\section{MATHEMATICAL MODEL}

The data regarding the essential BFB, DRI, food composition tables and minimum wage were used to build a mathematical model that would optimize the food choices so that nutrient requirements could be met.

\section{A. Decision Variables}

The 30 items present in the essential BFB were determined to be the decision variables and are represented in the following way:

$$
X_{i}=\text { grams of food item } i \text { to consume per day }
$$

Where:

$\mathrm{I}=\{1,2, \ldots, 30\}$

$17^{\text {th }}$ LACCEI International Multi-Conference for Engineering, Education, and Technology: "Industry, Innovation, And Infrastructure for Sustainable Cities and Communities", 24-26 July 2019, Jamaica. 


\section{B. Objective Function}

The objective function used aimed to minimize the grams of food consumed per day and was expressed as follows:

$$
\operatorname{Min} \mathrm{Z}=\sum_{i=1}^{I} X_{i}
$$

\section{Constraints}

The constraints used for the different models can be divided into 7 groups which are the following (constraints are shown with values pertaining to the third model):

1. DRI Macronutrient constraints: depict the minimum amount of the various macronutrients that must be consumed daily expressed in grams. Macronutrients include water, carbohydrates, fiber and protein (as presented below).

$$
\begin{aligned}
& \sum_{i=1}^{I} X_{i} \times W_{i} \geq 10,900 \\
& \sum_{i=1}^{I} X_{i} \times C h_{i} \geq 520 \\
& \sum_{i=1}^{I} X_{i} \times F b_{i} \geq 120 \\
& \sum_{i=1}^{I} X_{i} \times P r_{i} \geq 170
\end{aligned}
$$

2. DRI Vitamin constraints: depict the minimum amount of the various vitamins that must be consumed daily expressed in grams. Vitamins include Vitamin A, Vitamin C, Thiamin, Riboflavin, Niacin, Vitamin B6, Folate and Vitamin B12 (as presented below).

$$
\begin{aligned}
& \sum_{i=1}^{I} X_{i} \times V A_{i} \geq 0.0028 \\
& \sum_{i=1}^{I} X_{i} \times V C_{i} \geq 0.2550 \\
& \sum_{i=1}^{I} X_{i} \times T h_{i} \geq 0.0041
\end{aligned}
$$

$$
\begin{aligned}
& \sum_{i=1}^{I} X_{i} \times R b_{i} \geq 0.0042 \\
& \sum_{i=1}^{I} X_{i} \times N c_{i} \geq 0.054 \\
& \sum_{i=1}^{I} X_{i} \times B 6_{i} \geq 0.0046 \\
& \sum_{i=1}^{I} X_{i} \times F l_{i} \geq 0.0014 \\
& \sum_{i=1}^{I} X_{i} \times B 12_{i} \geq 0.00001
\end{aligned}
$$

3. DRI Elements constraints: depict the minimum amount of the various elements that must be consumed daily expressed in grams. Elements include Calcium, Iron, Magnesium, Phosphorus, Zinc, Potassium and Sodium (as presented below).

$$
\begin{aligned}
& \sum_{i=1}^{I} X_{i} \times \mathrm{Cal}_{i} \geq 4.6 \\
& \sum_{i=1}^{I} X_{i} \times F e_{i} \geq 0.0420 \\
& \sum_{i=1}^{I} X_{i} \times M g_{i} \geq 1.22 \\
& \sum_{i=1}^{I} X_{i} \times P h_{i} \geq 3.90 \\
& \sum_{i=1}^{I} X_{i} \times Z n_{i} \geq 0.035 \\
& \sum_{i=1}^{I} X_{i} \times K_{i} \geq 18.4 \\
& \sum_{i=1}^{I} X_{i} \times N a_{i} \geq 6
\end{aligned}
$$

4. UL Vitamin constraints: depict the maximum amount of the various vitamins that can be consumed daily express in grams to avoid negative side effects. These are expressed in a similar manner as constraint group 2 with the exception that it contains a less than or equal to sign.

5. UL Element constraints: depict the maximum amount of the various elements that can be 
consumed daily express in grams to avoid negative side effects. These are expressed in a similar manner as constraint group 3 with the exception that it contains a less than or equal to sign.

6. Cost constraint: depicts the maximum number of lempiras that can be spent on a single day across all food items considering the minimum wage of a company that has more than 151 employees in the agriculture economic sector. This constraint was only used in models 2 and 3.

$$
\sum_{i=1}^{I} X_{i} \times P_{i} \leq 255.84
$$

7. Portion Guidelines: depicts the Food Based Dietary Guidelines (FBDG) recommendations for Honduras regarding food item combination. The 30 food items were separated into 6 groups which are: meat, cereals and tubers, milk and eggs, fruit and vegetables, sugar and salt; and fats and oils used for cooking (as presented below). These constraints were only used in models 2 and 3 .

$$
\begin{aligned}
& \sum_{i=1}^{I} X_{i} \geq 102.86 \quad I=\{1,2,3,4,5\} \quad \text { (22) } \\
& \sum_{i=6}^{I} X_{i} \geq 438.29 \quad I=\{6,7,9,10,23\} \quad \text { (23) } \\
& \sum_{i=8}^{I} X_{i} \geq 457 \quad I=\{8,13,14,19,20,28,29\} \\
& \sum_{i=11}^{I} X_{i} \geq 1600 \quad I=\{11,12,15,16,17,18\} \\
& \sum_{i=21}^{I} X_{i} \leq 37.5 \quad I=\{21,27\} \\
& \sum_{i=25}^{I} X_{i} \geq 33.6 \quad I=\{25,26\}
\end{aligned}
$$

\section{RESULTS}

\section{A. Model\#1}

Result for the first model can be observed in table 4 .

Table 4

Model 1 summary

\begin{tabular}{|c|c|c|c|}
\hline Item & Grams/day & Grams/month & L./month \\
\hline Milk & 210.6 & $6,319.5$ & 129.9 \\
\hline Milk powder & 13.1 & 393.8 & 82.4 \\
\hline Fresh Cheese & 1.6 & 48.7 & 4.6 \\
\hline Yellow Onion & 174.9 & 5247.5 & 157.8 \\
\hline Tomato & 572.0 & $17,161.0$ & 447.4 \\
\hline Orange & 470.8 & $14,123.6$ & 288.4 \\
\hline Banana & 2.7 & 80.8 & 1.2 \\
\hline Salt & 1.6 & 46.7 & 0.8 \\
\hline Loaf of bread & 31.9 & 958.4 & 64.6 \\
\hline \multicolumn{3}{|c|}{ Total } & $1,177.04$ \\
\hline
\end{tabular}

The first model only included RDI and UI constraints for a single person (child between 1-3 years). Out of the 30 food items available in the essential BFB only 9 were chosen by the algorithm in order to fulfill nutritional requirements. Its worth noting that the results rely heavily on tomato and orange indicating that there should be a daily consumption of 572 and 470.8 grams of each respectively. A regular serving size of tomato is defined as approximately $128 \mathrm{~g}$, this would mean that children between the age of 1 and 3 should consume 3 portions of tomatoes daily. A similar trend can be observed for the orange and to a lesser extent milk and yellow onion.

No meat products are considered, and no oil or lard is assigned which would be needed to cook certain foods. At the same time the FBDG recommend a more varied diet. Another issue with the first model is that it does not consider the minimum wage information to determine if its possible to obtain all the food items for a month. The cost per month of the 9 items described would be of L.1,177.04.

The distribution of the first model would be hard to apply to population at risk due to the high repetition of food items and the fact that some staple Hondurans food items like corn tortilla, plantain and red beans are missing from the answer. 


\section{B. Model \#2}

Result for the second model can be observed in table 5 .

Table 5

Model 2 summary

\begin{tabular}{|c|c|c|c|}
\hline Item & Grams/day & Grams/month & L./month \\
\hline Beef Chop & 18.17 & 545.0 & 81.7 \\
\hline White fish & 7.55 & 226.4 & 13.7 \\
\hline Milk & 189.38 & $5,681.5$ & 116.8 \\
\hline Fresh Cheese & 21.11 & 633.3 & 59.7 \\
\hline Yellow Onion & 254.68 & $7,640.4$ & 229.8 \\
\hline Tomato & 380.78 & $11,423.4$ & 297.8 \\
\hline Potato & 107.91 & 3237.4 & 64.2 \\
\hline Orange & 500.70 & $15,020.9$ & 306.7 \\
\hline Salt & 2.19 & 65.6 & 1.1 \\
\hline Loaf of bread & 1.66 & 49.7 & 3.4 \\
\hline \multicolumn{2}{|c|}{ Total } & & 1174.8 \\
\hline
\end{tabular}

The second model which included the cost constraint and FBDG constraints for a single person (child between 1-3 years old). An extra item was added to the list when compared to the first model and a small decrease in total lempiras per month can also be seen; this coincides with the inclusion of a cost constraint; the algorithm will try to spend the less amount of money possible.

Other notable changes when compared with table 4 is the inclusion of two items from the meat group which are Beef Chop and White fish. The FBDG recommend that items from the meat group be consumed at least two times per week and that for an adequate nutrition and that food from every food group must be consumed. Tomato which was the food item with the highest value of grams per day in the first model experienced a reduction from 572 grams to 380.78 grams; other items such as orange and yellow onion saw their intake increase while loaf of bread was greatly reduced. These changes can be attributed to the fact that the new constraints require new items to be introduced.

Regarding the total cost the total per month would be of L.1,174.8 which is below the minimum wage of L. 7,674.11. Still, this scenario presents the requirements of a single child thus further analysis of a scenario closer to a real situation must be done. Staple foods for the country are still missing from the optimum solution as was with model \#1.

\section{Model \#3}

Result for the third model can be observed in table 6 .

Table 6

Model 3 summary

\begin{tabular}{|c|c|c|c|}
\hline Item & Grams/day & Grams/month & L./month \\
\hline Beef Chop & 73.75 & $2,212.4$ & 331.7 \\
\hline White fish & 37.86 & $1,135.9$ & 68.9 \\
\hline Milk & $3,926.45$ & $117,793.6$ & $2,420.7$ \\
\hline Tomato & $3,521.75$ & $105,652.4$ & $2,754.3$ \\
\hline Potato & 786.58 & $23,597.4$ & 468.2 \\
\hline Cabbage & $3,690.99$ & $110,729.8$ & $1,059.1$ \\
\hline Red beans & 59.50 & $1,784.9$ & 46.5 \\
\hline Lard & 33.60 & $1,008.0$ & 36.1 \\
\hline Salt & 8.96 & 268.8 & 4.5 \\
\hline \multicolumn{3}{|c}{ Total } & 7,190 \\
\hline
\end{tabular}

The third and final model was done based on a 4-person household that includes two parents (male and female both between 31 and 50 years old) and two children (male and female both between 9 and 13 years old). Nutritional requirements were added as a total, so everyone had their needs fulfilled each day; additionally, an extra constraint regarding lard and oil was added to factor in the necessity of cooking certain foods such as beef and fish.

Of the total number of items available in the essential BFB only 9 were chosen, the same number presented in model \#1. In contrast with said model it can be observed that this one includes items from all the food groups like the results of model \#2. New items incorporated in the list include red beans which is one of the staple foods of the country, cabbage and lard that is used to cook even if it does not add any nutritional value to the diet. The food item with the highest grams per day for the whole family unit is milk, followed by cabbage and tomato.

The tomato is present in every model and thus, it can be inferred that it possesses one of the highest nutritional benefits amongst all other food items of the essential BFB. The model assigns very few items and as with the other two models is missing staple foods that are widely consumed in the country. Constraints of cultural acceptability have been implemented in various studies and would need to be considered in the future so that the results include the aforementioned staple foods.

Regarding the total cost of the assigned items it can be observed that the monthly cost would be of L.7,190 for a 4person household. This value is almost the same as the highest minimum wage for the agriculture economic sector; if the minimum wage would decrease there would be a conflict between the constraints that would make the algorithm not find a solution where all constraints are satisfied. As was mentioned before great part of the population live in poverty or extreme poverty; this is an indication that there is a deficit in the prices of the essential BFB.

$17^{\text {th }}$ LACCEI International Multi-Conference for Engineering, Education, and Technology: "Industry, Innovation, And Infrastructure for Sustainable Cities and Communities", 24-26 July 2019, Jamaica. 


\section{CONCLUSIONS}

1. Linear programming can be successfully used to determine the optimum combination of items of a BFB in Honduras that would satisfy the nutritional requirements of a single person or a family unit. The changes observed in the results for each one of the three models highlights the importance of using this kind of engineering technique to solve problems in a more precise way.

2. Model \#1 presents shortcomings due to the fact that no cost constraint or FBDG constraints are present. Results are not indicative of a normal diet because of this.

3. Model \#2 presents a more satisfactory and varied diet but still ignores staple foods for the country, it adheres to the minimum wage in a successful manner, nevertheless the results only consider 1 child and not a family unit.

4. Further studies regarding the essential BFB of Honduras must consider culturally acceptable constraints so there is more variety to the food items selected which would make the model more useful. Even without considering culturally acceptable constraints it can be concluded that the minimum wage of the lowest paid economic sector is not enough for an average household as is shown in model \#3; this ties directly with the malnutrition problem that exist due to the fact that a household not only has to buy food but also has public services (such as water and energy), education and medical expenses amongst others that have to be taken care of.

\section{REFERENCES}

[1] World Food Programme. (2018, October). WFP Honduras Country Brief. Retrieved from WFP: https://docs.wfp.org/api/documents/WFP0000100839/download/? ga=2.116500678.1323367257.1548885442 1877786483.1541427092

[2] The World Bank. (2018, October 04). The World Bank in Honduras. Retrieved from http://www.worldbank.org/en/country/honduras/overview\#1

[3] Gobierno de la República de Honduras. (2019, January 9). Acuerdo Ejecutivo No. STSS-006-2019. La Gaceta, p. 12.

[4] Central Intelligence Agency. (n.d.). The World Factbook : Labor Force by Occupation. Retrieved February 5, 2019, from Cia: https://www.cia.gov/library/publications/the-worldfactbook/fields/219.html\#HO

[5] United Nations, Department of Economic and Social Affairs, Population Division. (2017). Household Size and Composition Around the World 2017 - Data Booklet. Retrieved from United Nations: http://www.un.org/en/development/desa/population/publications/pdf/agei ng/household_size_and_composition_around_the_world_2017_data_boo klet.pdf

[6] FAO and PAHO. (2017). Panorama of Food and Nutrition Security in Latin America and the Caribbean. Retrieved from Food and Agriculture Organization of the United Nations: http://www.fao.org/3/I7914EN/i7914en.pdf

[7] Secretaría de Desarrollo Económico. (2019, February). Precios Semanales - Canasta Básica Alimentaria. Retrieved from Secretaría de Desarrollo Económico: https://sde.gob.hn/2018/01/09/5592/

[8] Secretaría de Trabajo y Seguridad Social; Dirección General de Salarios. (2018). Informe Anual Mercado de Trabajo y Salario Mínimo 2018 - 2019. Retrieved from Secretaría de Trabajo y Seguridad Social: http://201.220.133.199/wp-content/uploads/2019/01/Informe-AnualMercado-de-Trabajo-y-Salario-Minimo-2018-2019.pdf

[9] Instituto Nacional de Estadística. (2018, June). Encuesta Permanente de Hogares de Propósitos Múltiples (EPHPM). Retrieved from INE Instituto
Nacional de Estadística: https://www.ine.gob.hn/index.php/25publicaciones-ine/87-encuesta-permanente-de-hogares-de-propositosmultiples-ephpm

[10] FAO; IFAD; UNICEF; WFP and WHO. (2018). The State of Food Security and Nutrition in the World. Building climate resilience for food security and nutrition. Rome: FAO. Retrieved from fao: http://www.fao.org/state-of-food-security-nutrition/en/

[11] Word Health Organization. (2015, November 19). Stunting in a nutshell. Retrieved from Word Health Organization: https://www.who.int/nutrition/healthygrowthproj_stunted_videos/en/

[12] Taha, H. A. (2017). Investigación de operaciones. Pearson.

[13] Almira Arnaut-Berilo, A. D. (2017). A NUTRITIONAL ANALYSIS OF THE FOOD BASKET IN BIH: A LINEAR PROGRAMMING APPROACH. South East European Journal of Economics and Business, 12(1), 104-113.

[14] Nykänen, E.-P. A., Dunning, H. E., Aryeetey, R. N., Robertson, A., \& Parlesak, A. (2018). Nutritionally Optimized, Culturally Acceptable, CostMinimized Diets for Low Income Ghanaian Families Using Linear Programming. Nutrients, 10(461).

[15] Parlesak, A., Tetens, I., Jensen, J. D., Smed, S., Blenkus, M. G., Rayner, M., , . Robertson, A. (2016). Use of Linear Programming to Develop CostMinimized Nutritionally Adequate Health Promoting Food Baskets. PLoS ONE, 11(10).

[16] Santos, Q. d., Sichieri, R., Darmon, N., Maillot, M., \& Verly-Junior, E. (2017). Food choices to meet nutrient recommendations for the adult Brazilian population based on the linear programming approach. Public Health Nutrition, 21(8), 1538-1545.

[17] Donati, M., Menozzi, D., Zighetti, C., Rosi, A., Zinetti, A., \& Scazzina, F. (2016). Towards a sustainable diet combining economic, environmental and nutritional objectives. Appetite, 106, 48-57.

[18]SESAL, OMS, FAO, Visión mundial honduras, INCAP. (2013). Guías Alimentarias para Honduras. Retrieved from http://www.fao.org/nutrition/education/food-based-dietaryguidelines/regions/countries/honduras/es/

[19] INCAP, OPS. (2012). Tabla de Composición de Alimentos de Centroamérica.

[20] National Institutes of Health. (n.d.). Nutrient Recommendations: Dietary Reference Intakes (DRI). Retrieved from National Institutes of Health Office of Dietary Suplements: https://ods.od.nih.gov/health_information/dietary_reference_intakes.aspx

$17^{\text {th }}$ LACCEI International Multi-Conference for Engineering, Education, and Technology: "Industry, Innovation, And Infrastructure for Sustainable Cities and Communities", 24-26 July 2019, Jamaica. 